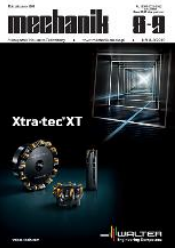

How to cite this article:

Authors: Maciej Cader, Marcin Osiak

Title of article: „Cooling channel design using immediate computer simulations and additive techniques”

Mechanik, No. 8-9 (2019)

DOI: https://doi.org/10.17814/mechanik.2019.8-9.74

\title{
Cooling channel design using immediate computer simulations and additive techniques
}

\author{
MACIEJ CADER \\ MARCIN OSIAK *
}

* Dr inż. Maciej Cader, mcader@piap.pl, https://orcid.org/0000-0003-0256-7214 - Przemysłowy Instytut Automatyki i Pomiarów PIAP, Warszawa, Polska

Inż. Marcin Osiak, marcinosiak96@gmail.com, https://orcid.org/0000-0001-5624-6921 - Politechnika Warszawska, Warszawa, Polska

The methodology for designing of the prototype of cooling channel tailored to work with printing head mounted in industrial 3D printer is presented. Modern tools to optimize mechanical structures using so-called immediate simulations - ANSYS Discovery - and additive methods as a tool for the production of optimized components were used. Paper includes results of application research which were verified by non-contacts experimental methods like thermovision measurements and temperatures control at selected points of channel.

KEYWORDS: prototyping, 3D printing, optimization, parts production, computational simulations, air flow

\section{Introduction}

Fused Deposition Modeling (FDM) is currently the most popular method of additive manufacturing [1]. It gives unique possibilities of producing the ultra-light machine parts made of high-strength polymers and composites [2,3]. These parts are widely used in prototype building as well as in the automotive, aviation and space industries.

FORIND 4.0 is a representative example of a machine working with the use of the FDM technique and meeting the industrial requirements aimed at stabilizing the processing conditions of polymeric materials.

It was developed at the PIAP institute, using inspiration from the products of the Stratasys corporation $[4,5]$.

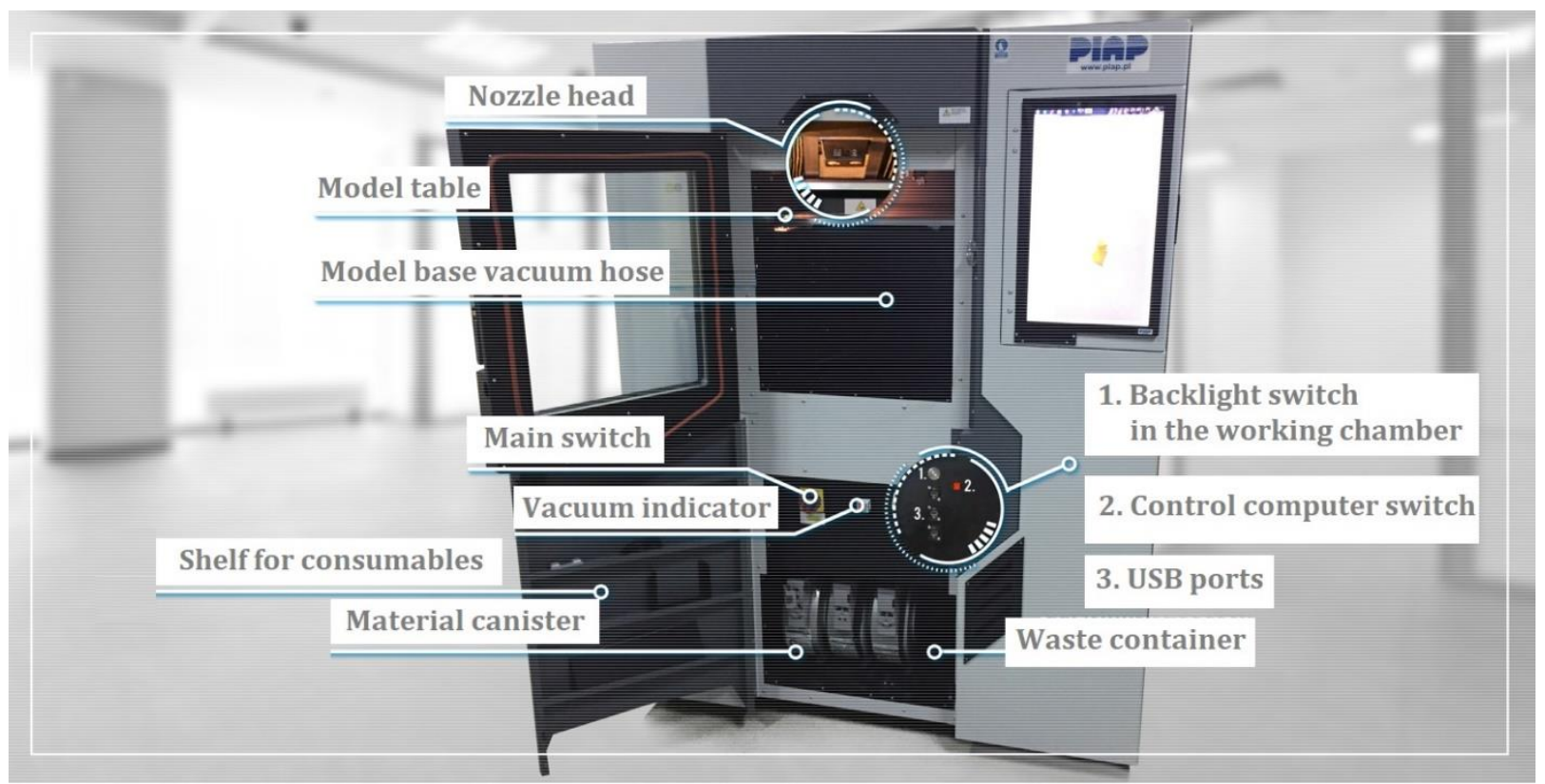

Fig. 1. FORIND 4.0 machine developed at PIAP 
One of the most important components in this type of machine is the nozzle head (fig. 1), that is responsible for the key process in the FDM method - polymerization of the polymer. Plasticizing occurs under strictly defined temperature conditions and temperature distributions along the entire extruder (fig. 2). Boundary values of these distributions depend on, among others, properties of the selected polymer [6]. The head in industrial FDM machines works both in the cold and hot zone - in the working chamber (fig. 3). Therefore, it is crucial to balance the head temperature by appropriate heating (using integrated heaters) and cooling (through cooling channels).

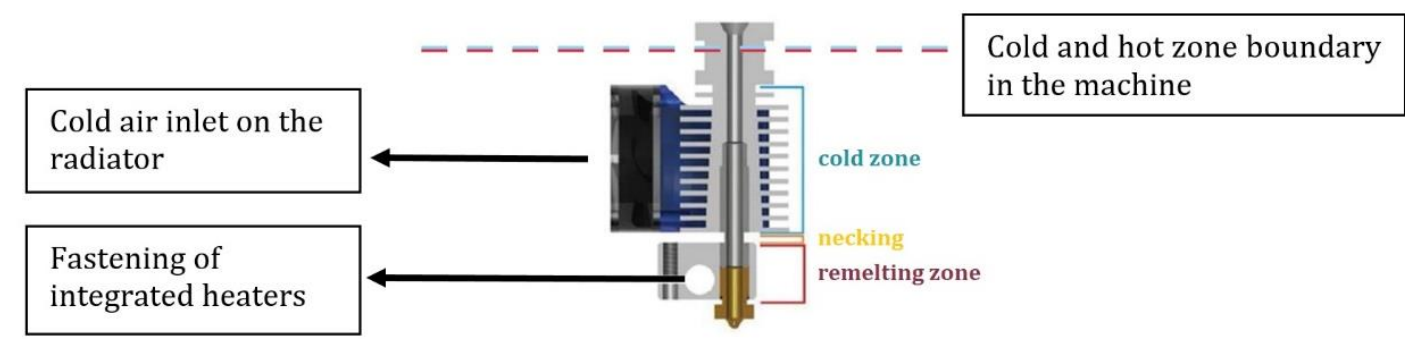

Fig. 2. Cross-section through plasticizing and transferring nozzle of a polymer [7]

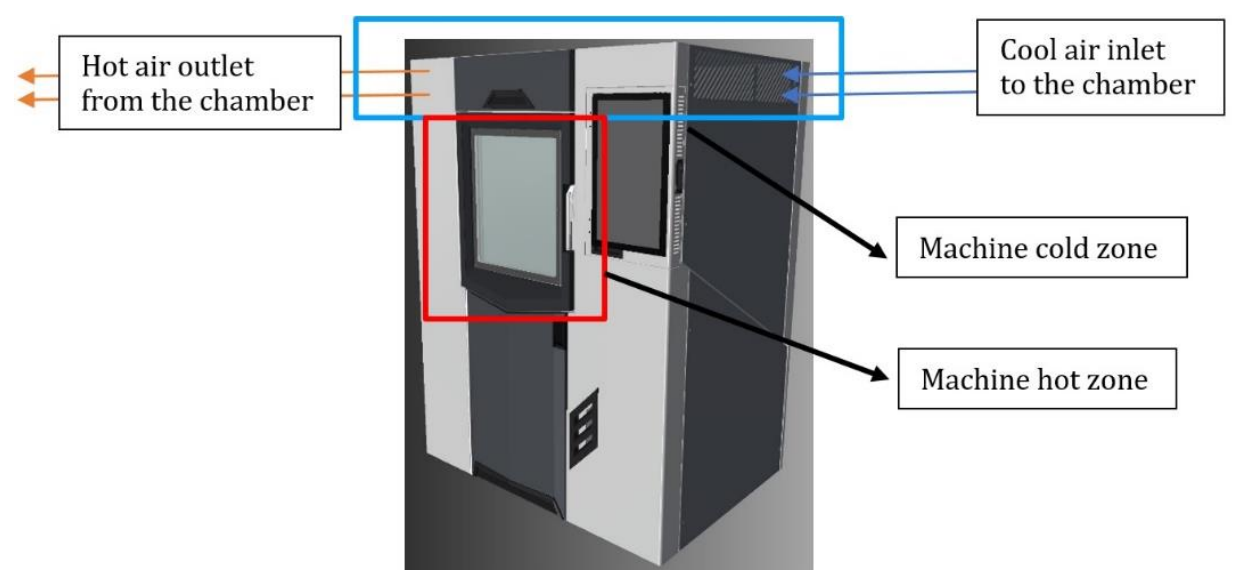

Fig. 3. Distribution of hot and cold zones and ventilation direction of the machine crane chamber

\section{Problem formulation and research goal}

The main purpose of the application research was to optimize the design of the cooling channel (fig. 4) in such a way that it draws cool air from the upper cold zone and transfers it with the smallest possible losses to the air inlet on the radiator, where the support fan is installed. The main assumption was to achieve a minimum for the difference in air temperature at the outlet and inlet of the cooling channel.

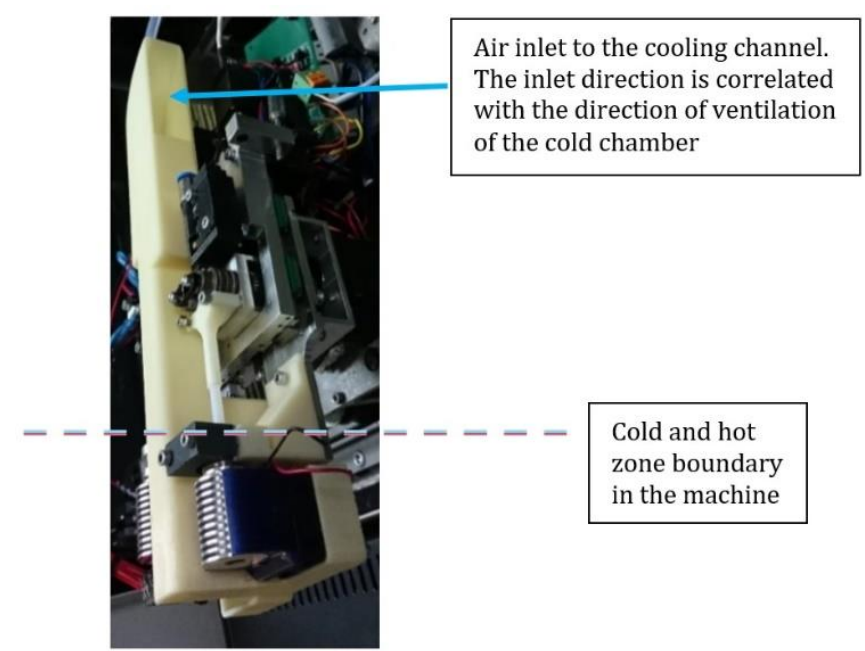

Fig. 4. The first - non-optimal - prototype of the cooling channel installed in the reference measurement machine 
The design criterion was defined as searching for the shape of the cooling channel geometry, for which the air flow will be laminar over the longest section, which should ensure that the objective function - the optimum cooling - is achieved.

Design work uses a modern ANSYS Discovery tool that allows to perform rapid simulations. This tool is based on a gridless method, due to which it is possible to quickly modify the structure parameters and update the calculation results on a regular basis. FDM technology was chosen as the method of cooling channel production. In this way, by topological design consisting in modification of selected geometry parameters and following the resulting shape of the cooling channel, the shape of the cooling module focused on additive manufacturing was developed. Polycarbonate from Stratasys and the FORTUS $400 \mathrm{mc}$ machine were selected for production [8].

\section{Methodology of application research}

Application research began with a study of the distribution of air flows and temperature for the cold zone of the machine. For this purpose, the body of the zone was mapped and the work of four fans was modeled - two injecting air into the cold chamber of the machine and two sucking air from it (fig. 3).

Based on the manufacturer's data on the fans used in the SUNON DP 202A, the average flow rate, equal to $0.037 \mathrm{~m}^{3} / \mathrm{s}$, and the air inlet speed of $4.26 \mathrm{~m} / \mathrm{s}$ were determined using classical formulas. Based on the boundary conditions and chamber geometry, the space cooling air flow was examined.

For the needs of the first simulation tests, it was assumed that the machine works at the temperature of $25^{\circ} \mathrm{C}$, which occurs in the entire zone. The purpose of the first study was to determine the value of air velocity in selected and characteristic (cylindrical) areas of the chamber. Location of the symmetry axis of the cylindrical areas is shown in fig. 5. For example: the coordinates of the position of the axis of cylinder No. 1 are: $X=207, Y$ $=123$ and the axis of cylinder No. $2: X=414, Y=123$. Representative results of air flow velocity distribution tests are presented in fig. 6.

The air temperature in the presented (cylindrical) areas was measured on the real object. Results were averaged. Mean values from simulation analyses of the speed distribution determined in the planes passing through the axes of the reference rollers were also averaged (fig. 6). Following data were obtained: $v_{\text {śr }}=1.33 \mathrm{~m} / \mathrm{s}$ and $t_{\text {śr }}=30^{\circ} \mathrm{C}$. These values were adopted for further testing as boundary conditions for the designed cooling channel.

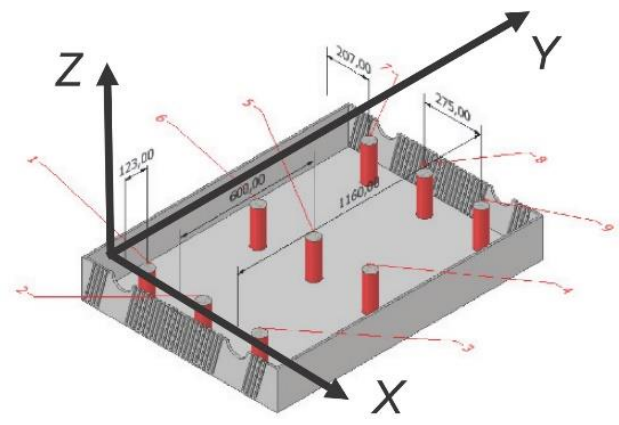

Fig. 5. Measuring places (space limited by red rollers) of the air flow velocity distribution in the cold zone of the machine

a)

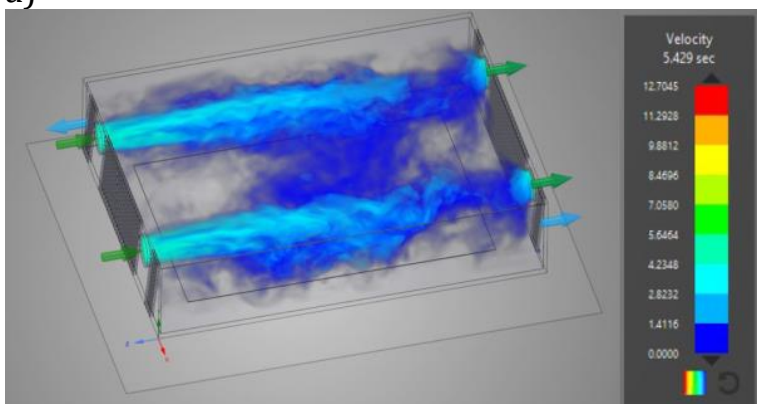

b)

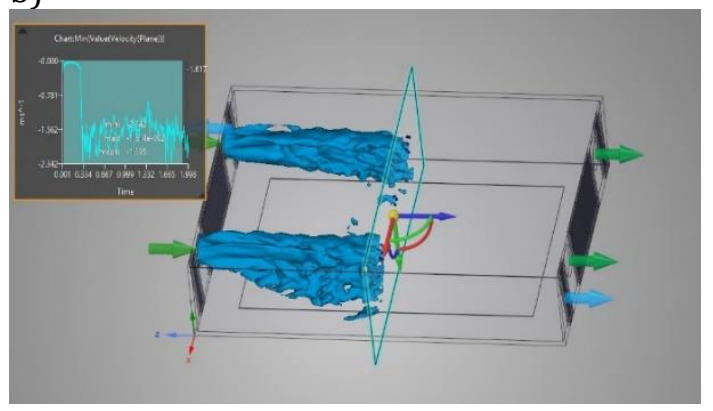

Fig. 6. Representative result of the distribution of air flow speed through a cold zone: a) speed distribution for the entire zone, b) air speed distribution in the cross section determined by the zone symmetry plane 
In the subsequent step, the temperature distribution on the cooling channel prototype that was installed in the machine, was identified. The measurement results were applied to the channel simulation model. Fig. 7 shows how to measure the temperature distribution for the cool part of the cooling channel and transfer the measured values to a computer model.

The last element of the complementary definition of the boundary conditions was the calculation of the speed and expenditure for the fan mounted directly on the nozzle radiator. Based on the manufacturer's information and classic formulas, the average air speed at the outlet of the channel was calculated: $5 \mathrm{~m} / \mathrm{s}$ and the average flow rate: $0.00307 \mathrm{~m}^{3} / \mathrm{s}$.

a)

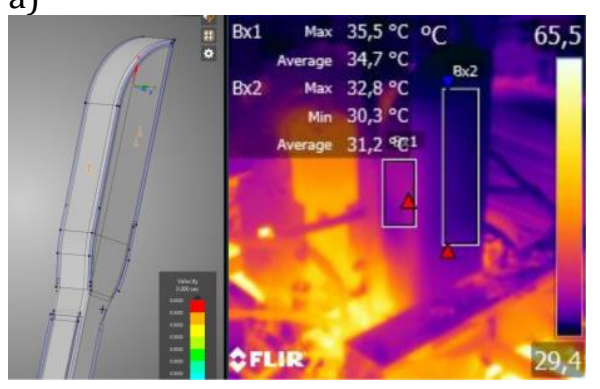

b)

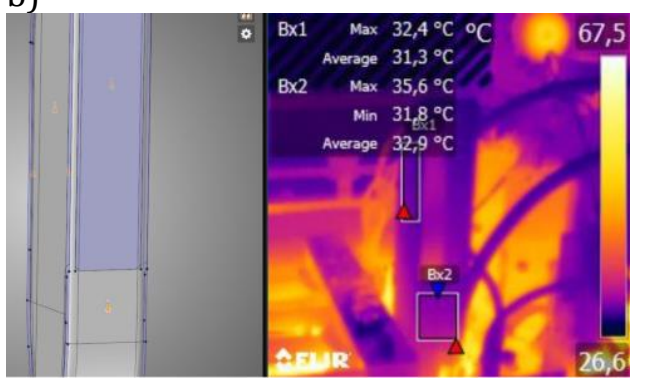

Fig. 7. Identification and definition of boundary conditions for individual elements of external geometry of the computer model of the cooling channel

\section{Research results and conclusions}

Research aimed at selecting the right geometry was carried out, changing selected parameters of the cooling channel shape (geometry). The working chamber of the machine was at $85^{\circ} \mathrm{C}$, the temperature in the cold zone was $30^{\circ} \mathrm{C}$, according to results of measurements of the real object. The results of four selected and representative iterations of the cooling channel solutions are shown in fig. 8. Geometry of the first version of the cooling channel (fig. 9a) and the target channel (fig. 9b) is also shown.

a)

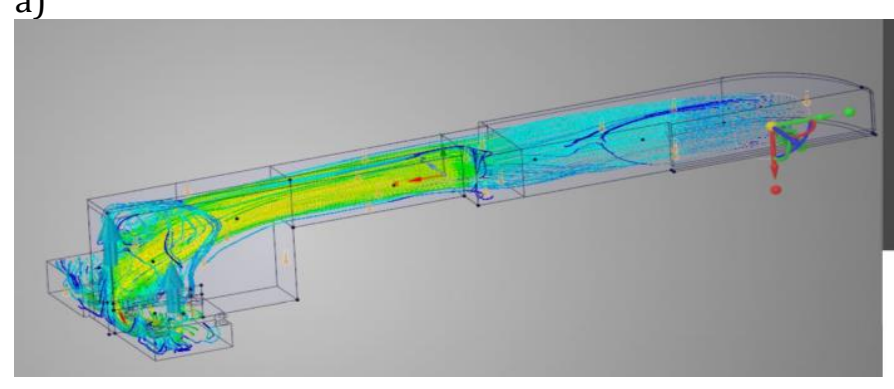

c)

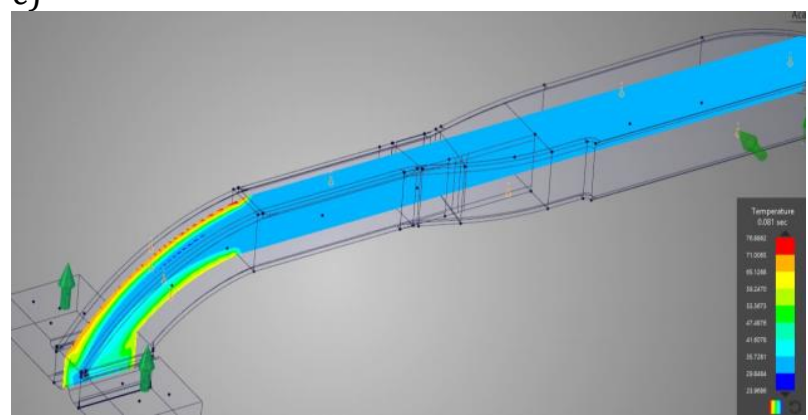

b)

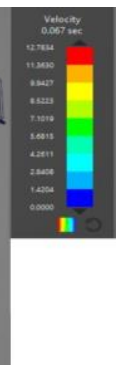

d)

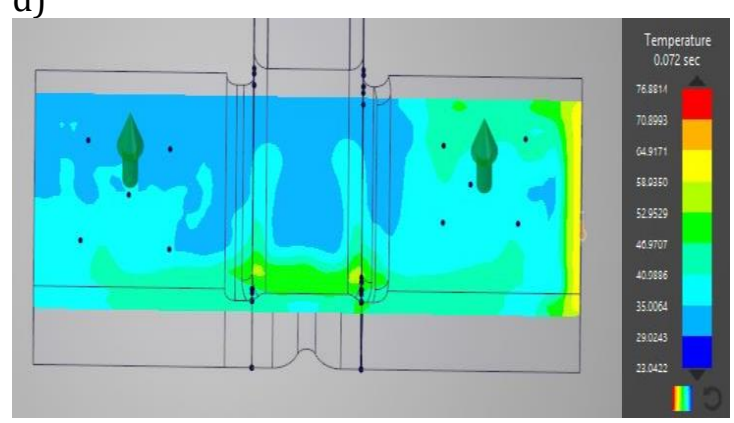

Fig. 8. Results of two representative iterations of solutions - initial (a, b) and final (c, d): a) strongly disturbed air flow lines; the inlet and outlet flow is strongly turbulent, b) the temperature distribution at the outlet of the cooling channel - the average temperature is $57^{\circ} \mathrm{C}$, c) shape of the cooling channel has been changed - from circular to rectangular; narrowing transitions were relaxed; the flow exhibits laminar features over almost the entire length of the channel, d) temperature distribution at the outlet of the cooling channel - average temperature is $39^{\circ} \mathrm{C}$ 
Figures 8a-b show the results of simulation tests for the prototype channel, while figs. 8c-d show results of tests for the target channel. Similarly, fig. 9 shows the characteristic dimensions and shapes of both cooling channel geometries.

As a result of application tests aimed at selecting the effective shape of the cooling channel, the channel geometry was determined for the assumed boundary and technical conditions of the housing. The channel maintains laminar flow almost along its entire length except for the last section - approximately $15 \mathrm{~mm}$ from the outlet surface. Due to this, the average temperature at the outlet of the channel installed in the working machine is $41^{\circ} \mathrm{C}$, which is $2^{\circ} \mathrm{C}$ higher than the one determined as a result of simulation tests and $11^{\circ} \mathrm{C}$ higher than the inlet air temperature.

Measurements on the real object were carried out with a thermal imaging camera and a pyrometer. The pyrometer served as a verifier of results obtained by the thermovision method. The point measurement was made at nine control points of the air outlet area from the cooling channel marked with a white square (fig. 10).

a)
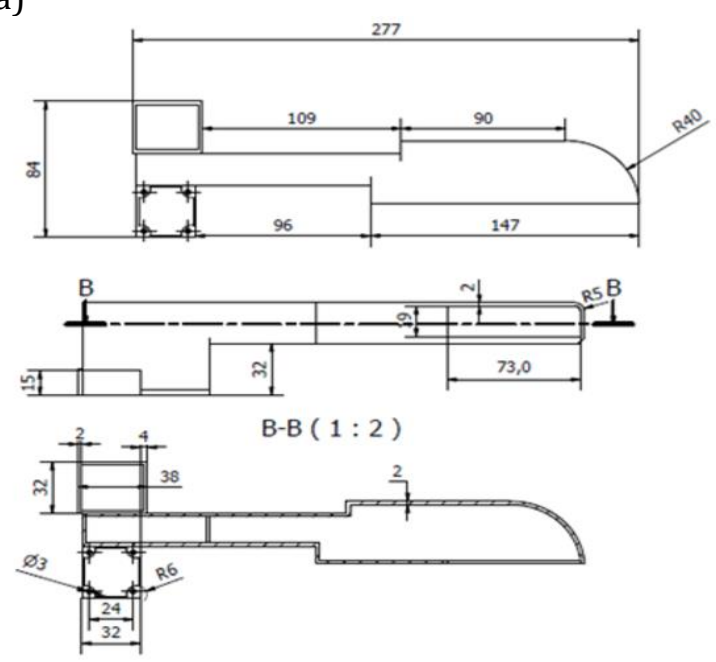

b)
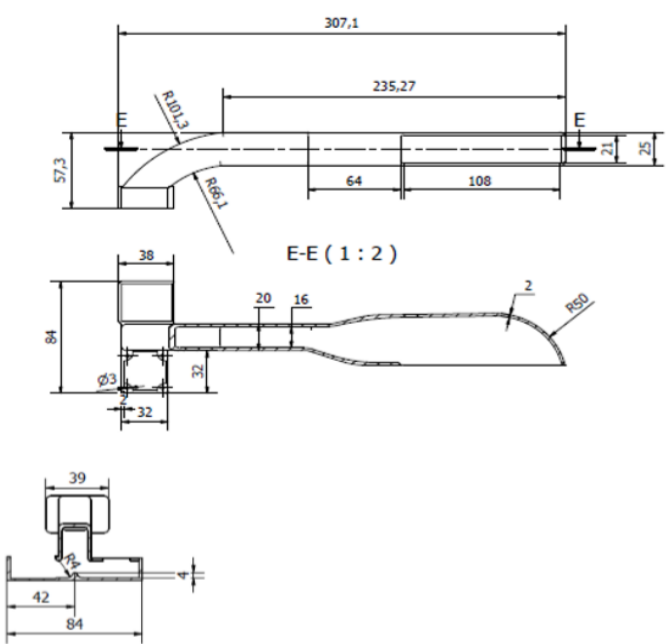

Fig. 9. Cooling channel geometry: a) output and b) target

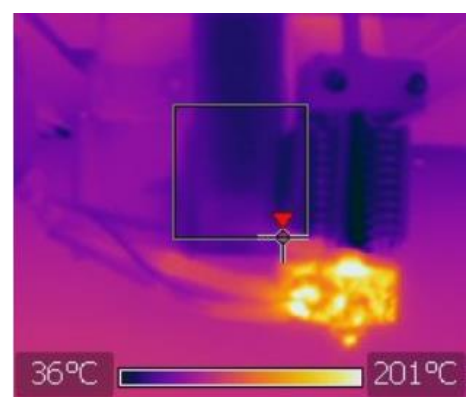

Fig. 10. Thermovision measurement of the place

\section{REFERENCES}

[1] Wohlers Report. "3D Printing and Additive Manufacturing State of the Industry". Annual Worldwide Progress Report. USA: Wholers Associates, 2018.

[2] Górski F., Wichniarek R., Kuczko W., Zawadzki P., Buń P. "Strength of ABS parts produced by fused deposition modelling technology - a critical orientation problem". Advances in Science and Technology Research Journal. 9, 26 (2015): 12-19. DOI: https://doi.org/10.12913/22998624/2359.

[3] Górski F., Wichniarek R., Kuczko W. "Influence of process parameters on dimensional accuracy of parts manufactured using Fused Deposition Modeling technology". Advances in Science \& Technology Research Journal. 7, 19 (2013): 27-35. DOI: https://doi.org/10.5604/20804075.1062340.

[4] https://www.stratasys.com/3d-printers/fortus-380mc-450mc (access: 10.04.2019).

[5] https://www.stratasys.com/3d-printers/stratasys-f900 (access: 10.04.2019).

[6] https://www.stratasys.com/materials (access: 10.04.2019).

[7] http://microfabricator.com/articles/view/id/537febea9aad9d097f000001/e3d-v6-hotend-released (access: 10.04.2019).

[8] https://www.stratasys.com/resources/search/white-papers/fortus-360mc-400mc (access: 10.04.2019). 